\title{
Diet quality is associated with reduced risk of hypertension among Inner Mongolia adults in northern China
}

\author{
Xuemei Wang ${ }^{1,2}$, Aiping Liư ${ }^{3}$, Maolin $\mathrm{Du}^{2}$, Jing Wu${ }^{4}$, Wenrui Wang ${ }^{5}$, Yonggang Qian ${ }^{5}$, \\ Huiqiu Zheng ${ }^{2}$, Dan Liu ${ }^{2}, \mathrm{Xi} \mathrm{Nan}{ }^{2}$, Lu Jia ${ }^{2}$, Ruier Song ${ }^{2}$, Danyan Liang ${ }^{2}$, Ruiqi Wang ${ }^{2}$ \\ and Peiyu Wang ${ }^{3, *}$ \\ 'Department of Nutrition and Food Hygiene, School of Public Health, Peking University Health Science Center, Beijing, \\ People's Republic of China: ${ }^{2}$ Department of Health Statistics, School of Public Health, Inner Mongolia Medical University, \\ Hohhot, People's Republic of China: ${ }^{3}$ Department of Social Medicine and Health Education, School of Public Health, \\ Peking University Health Science Center, No. 38 Xueyuan Road, Haidian District, Beijing 100191, People's Republic of \\ China: ${ }^{4}$ National Center for Chronic and Non-Communicable Disease Control and Prevention, Chinese Center for \\ Disease Control and Prevention, Beijing, People's Republic of China: ${ }^{5}$ Department of Chronic Disease Control and \\ Prevention, Inner Mongolia Center for Disease Control and Prevention, Hohhot, People's Republic of China
}

Submitted 25 February 2019: Final revision received 6 June 2019: Accepted 2 July 2019; First published online 5 November 2019

\begin{abstract}
Objective: The present study investigated the association between dietary patterns and hypertension applying the Chinese Dietary Balance Index-07 (DBI-07).

Design: A cross-sectional study on adult nutrition and chronic disease in Inner Mongolia. Dietary data were collected using $24 \mathrm{~h}$ recall over three consecutive days and weighing method. Dietary patterns were identified using principal components analysis. Generalized linear models and multivariate logistic regression models were used to examine the associations between DBI-07 and dietary patterns, and between dietary patterns and hypertension.

Setting: Inner Mongolia ( $n$ 1861).

Participants: A representative sample of adults aged $\geq 18$ years in Inner Mongolia. Results: Four major dietary patterns were identified: 'high protein', 'traditional northern', 'modern' and 'condiments'. Generalized linear models showed higher factor scores in the 'high protein' pattern were associated with lower DBI-07 $(\beta \mathrm{LBS}=-1.993, \beta \mathrm{HBS}=-0.206, \beta \mathrm{DQD}=-2 \cdot 199$; all $P<0.001)$; the opposite in the 'condiments' pattern $(\beta \mathrm{LBS}=0.967, \quad \beta \mathrm{HBS}=0.751, \quad \beta \mathrm{DQD}=1.718 ; \quad$ all $P<0.001)$. OR for hypertension in the highest quartile of the 'high protein' pattern compared with the lowest was 0.374 (95\% CI 0.244, 0.573; $\left.P_{\text {trend }}<0.001\right)$ in males. OR for hypertension in the 'condiments' pattern was 1.663 (95\% CI 1.113, 2.483; $\left.P_{\text {trend }}<0.001\right)$ in males, 1.788 (95\% CI 1.155, 2.766; $\left.P_{\text {trend }}<0.001\right)$ in females. Conclusions: Our findings suggested a higher-quality dietary pattern evaluated by DBI-07 was related to decreased risk for hypertension, whereas a lower-quality dietary pattern was related to increased risk for hypertension in Inner Mongolia.
\end{abstract}

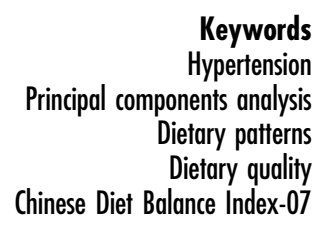

Hypertension is a global public health issue. The total number of adults with hypertension reached 1.13 billion worldwide in 2015, up from 0.594 billion in 1975, and low- and middle-income countries contributed most to this increase $\mathrm{e}^{(1)}$. The hypertension prevalence rate in China is increasing. A survey by Wang et al. in 2014 showed that the national adjusted hypertension prevalence rate was $29.6 \%^{(2)}$, which was higher than that in $2002(18 \%)^{(3)}$. Hypertension is an independent disease and an important risk factor for cardiovascular and cerebrovascular diseases.
An investigation by the WHO on causes of death showed that about 17 million people die of CVD each year (which constitute about one-third of the total deaths); of all the cardiovascular causes of death, $47 \%$ comprised heart disease and $54 \%$ comprised stroke owing to hypertension ${ }^{(4,5)}$.

Dietary factors are closely related to the development of hypertension. A diet containing vegetables, fruits and low amounts of salt and fat helps to prevent or reduce hypertension. Excessive Na consumption is a risk factor for hypertension. Researchers are paying increasing attention to the 
association between dietary patterns and disease. The Mediterranean dietary pattern can lower hypertension ${ }^{(6)}$ and chronic heart failure ${ }^{(7)}$. The Western dietary pattern is significantly associated with increased risk of maturity-onset CHD and stroke. Among different dietary patterns, the Dietary Approaches to Stop Hypertension (DASH) dietary pattern is generally recognized as an effective way to prevent and control hypertension. However, the DASH diet is not wholly appropriate for China, as it features fruits, vegetables, whole grains, other mineral-rich foods, low saturated fat consumption and low Na consumption ${ }^{(8)}$. The traditional dietary pattern in China ${ }^{(9)}$, particularly in northern China, is characterized by high consumption of wheat and starch and low consumption of protein products such as pork, beef, poultry, aquatic products and dairy products. This diet is very different from the DASH dietary pattern. In addition, the DASH dietary pattern focuses only on the effect of specific foods and nutrients on hypertension and does not consider the effect of overall dietary quality.

Located in northern China, Inner Mongolia is a minority community containing forty-nine ethnic groups, including the Han nationality and the Mongol nationality. Different ethnic groups have different genetic characteristics and food culture. Inner Mongolia has high prevalence rates for metabolic diseases related to nutrition, such as hypertension $^{(10)}$. To address the relationship between diet and hypertension in Inner Mongolia, the association between dietary patterns and the prevalent risks of hypertension was explored in the present study. Chinese Dietary Balance Index-07 (DBI-07) scores were used to evaluate the quality of the main dietary patterns.

\section{Methods}

\section{Study design}

The present study was a surveillance survey of chronic disease and nutrition in Chinese adults in Inner Mongolia in 2015. The survey was conducted across eight monitoring sites in Inner Mongolia. Participants comprised residents of urban, farming, pastoral and forest areas, and from different age and ethnic groups. The cross-sectional study investigated dietary and non-dietary factors: general demographics, lifestyle, hypertension prevalence rate, dietary behavioural habits and daily food intake, by multistage-stratified cluster-random sampling among those aged $\geq 18$ years.

The survey was approved by the Ethical Committee of the National Institute for Nutrition and Food Safety, Chinese Center for Disease Control and Prevention. All participants provided written informed consent before the start of the investigation.

\section{Dietary data collection}

A $24 \mathrm{~h}$ recall and weighing method over three consecutive days was used to collect dietary data. This dietary survey was recommended by the Chinese Dietary Guidelines for chronic disease and nutrition surveillance in Chinese adults, and aimed to know about the residents' intakes of nutrients and foods. Every household member (aged 2 years or over) was investigated. In the $24 \mathrm{~h}$ recalls, participants recalled and described all food and alcohol consumption for three consecutive days. Information about consumption of condiments such as salt and soya sauce, and cooking oil, was collected using a weighing method. Condiments purchased and wasted were also recorded.

Drinking frequency, type (liquor with high alcohol content, liquor with low alcohol content, beer, yellow rice wine, rice wine, wine) and average drinking amount were measured. The average daily alcohol consumption was calculated according to the Manual of Chinese Chronic Disease and Nutrition Surveillance Survey ${ }^{(11)}$. Participant height and weight were directly measured by trained and evaluated workers. Blood and urine samples were also collected. The laboratory director organized the qualitycontrol sample assessment at a field laboratory.

\section{Chinese Dietary Balance Index-07}

The Chinese DBI-07 is a method for evaluating dietary structure and quality based on the Chinese Dietary Guidelines, which consists of seven components: (i) cereals; (ii) vegetables and fruits; (iii) dairy products, soyabeans and soyabean products; (iv) animal foods; (v) condiments and alcohol; (vi) dietary variety; and (vii) drinking-water ${ }^{(12,13)}$. The DBI-07 evaluation of intake quality for different foods is based on the consumption patterns of individuals with different energy intakes. A score of 0 for each component indicates that the recommended intake has been met. Positive scores (0 to 12) are used to evaluate excessive intake of alcoholic beverages and condiments that should be reduced or limited according to the guidelines. Negative scores $(-12$ to 0$)$ are used to evaluate insufficient intakes of vegetables and fruits, dairy products, soyabeans and soyabean products, food variety and drinking-water that should be consumed sufficiently or in quantity according to the guidelines. Both positive and negative scores are used to evaluate intake of cereals ( -12 to 12$)$ and animal foods ( -12 to 8$)$, which should be consumed in appropriate amounts according to the guidelines. To reflect the different nutritional needs of people with different energy consumption, the scores for cereals, vegetables, fruit, dairy products, soyabeans and soyabean products, animal foods and condiments are based on seven energy intake levels. Twelve food subgroups are used to evaluate the food variety recorded by the DBI-07: (i) rice and rice products; (ii) wheat and wheat products; (iii) corns, coarse grains, starchy roots and their products; (iv) dark-coloured vegetables; (v) light-coloured vegetables; (vi) fruits; (vii) soyabeans and soyabean products; (viii) dairy products; (ix) livestock meat and meat products; (x) poultry; (xi) eggs; and (xii) fish and shellfish. If food intake amounts meet the lowest recommended amounts, the 
score for this subgroup is 0 ; if not, -1 . The lowest recommended intake amounts are $5 \mathrm{~g}$ for soyabeans and soyabean products and $25 \mathrm{~g}$ for other food subgroups. The score for food variety ranges from -12 to 0 . An indicator of dietary quality is calculated from the scores on different parts of the DBI-07.

The higher-bound score (HBS) is calculated by adding all positive scores as an indicator of excessive food intake. The lower-bound score (LBS) is calculated by adding the absolute values of all negative scores as an indicator of insufficient food intake. Diet quality distance (DQD) is calculated by adding the absolute values of both positive and negative scores. The possible ranges for total score, HBS, LBS and DQD scores are -72 to 44,0 to 32,0 to 72 and 0 to 84 , respectively. Each indicator is divided into five levels for convenience: (i) 'no problem' (a score of 0); (ii) 'almost no problem' (less than $20 \%$ of the total score); (iii) 'low level' (20-40\% of the total score); (iv) 'moderate level' (40-60\% of the total score); and (v) 'high level' (>60\% of the total score). The total score of each DBI-07 component is divided by the total score of LBS, HBS and DQD to assess their contribution rate and how much each food subgroup affects dietary quality (see online supplementary material, Supplemental Table S1).

\section{Definition of bypertension}

The main outcome indicator was hypertension. Meeting one of the following conditions was considered to indicate hypertension. The first condition was self-reported hypertension; that is, having a diagnosis of hypertension and currently receiving hypertension treatment ${ }^{(14)}$. The second condition was field-measured hypertension, assessed as the average of three blood pressure measurements carried out by trained investigators and defined as average systolic blood pressure $\geq 140 \mathrm{mmHg}$ and/or average diastolic blood pressure $\geq 90 \mathrm{mmHg}$.

\section{Other variables}

Age was categorized as follows: <35, 35-44, 45-54, 55-64 and $\geq 65$ years. Participant household registration place was categorized as urban or rural. Based on regional characteristics, ethnicity groups were categorized as Han, Mongolian or other minorities (i.e. all minorities living in Inner Mongolia except Han and Mongolian). Educational level was categorized as low (primary school or lower), medium (junior high school) or high (senior high school and above). Marital status was categorized as married, unmarried or widowed/divorced.

Smoking status was categorized as non-smoker (never having smoked previously), ex-smoker (previously smoked but has quit) or current smoker (has smoked at least 1 cigarette/d for more than 1 year and smokes now).

Physical activity was assessed by the questionnaire, which addressed three activity categories with twenty-six items: twenty items on physical activity state, four items on resting state and two items on sleeping state. The items asked participants what kind of activities they engaged in, the frequency of activities per week and the total time spent on activities per day. Physical activities were scored using the weighting procedure recommended by the Physical Activity Guidelines for Americans ${ }^{(15)}$.

BMI was categorized as three groups according to the recommended standard issued by a working group on obesity in China ${ }^{(16)}$. BMI was categorized as normal or underweight $\left(\mathrm{BMI}<23.9 \mathrm{~kg} / \mathrm{m}^{2}\right)$, overweight $(\mathrm{BMI}=24 \cdot 0$ $27.9 \mathrm{~kg} / \mathrm{m}^{2}$ ) or obese $\left(\mathrm{BMI} \geq 28.0 \mathrm{~kg} / \mathrm{m}^{2}\right)$. The normal and underweight categories were combined into one as there were too few people in the standard underweight category.

\section{Statistical analysis}

Continuous variables were shown as means and standard deviations. ANOVA was used for group comparisons. Categorical variables were expressed as numbers and percentages and were analysed using the $\chi^{2}$ test.

Principal components analysis was used to derive food patterns based on the twenty-nine food groups. The varimax rotation (orthogonal rotation) was used to extract factor loadings. Factors were selected based on their eigenvalues ( $>1.00)$. The number of dietary patterns was determined based on scree plots, reasonability of food combination and variance contribution rate. Factor scores for each pattern were calculated by adding the coefficient of the factor loading and the standardized daily intake amounts of every kind of food that was related to each pattern. Dietary patterns were defined according to absolute factor loading values $>0.2$ for each factor on different food types. Dietary patterns were named by combining the food composition characteristics of the dietary pattern with the main food types included. Based on quartiles, factor scores were classified into four groups, quartiles Q1, Q2, Q3 and Q4, in ascending order of factor scores. The higher the score, the more consistent the individual dietary intake condition and dietary pattern were; the lower the score, the less likely the individual dietary intake condition fitted the dietary pattern.

Using generalized linear models, LBS, HBS, DQD being the dependent variables and dietary patterns being the independent variable, the quality of dietary patterns was evaluated after adjusting for other confounders. Multivariate logistic regression models were used to examine the association between dietary patterns and hypertension. The 'Forward: LR' method was used to select independent variables. With $\alpha=0.05$ as the significance level, $P \leq 0.05$ was considered statistically significant. The statistical software package IBM SPSS Statistics version 19.0 was used for all analyses.

\section{Results}

\section{Participant characteristics}

A total of 1861 participants were included in the present study: 889 (47.77\%) men and 972 (52.23\%) women. The 
mean age was 52.5 years. Of participants, 914 (49.11\%) were hypertension patients, 463 were male (52.08\%) and 451 were female ( $46 \cdot 40 \%$ ). A total of $58.41 \%$ of participants were from rural areas and 18.21\% were minorities; $45 \cdot 89 \%$ had primary school education or no formal education. Among the participants, the rate of excessive drinking was 3.39\%; 587 (31.54\%) and 109 (5.86\%) were identified as current smokers and ex-smokers, respectively; and 762 $(41.41 \%)$ were more likely partake in no exercise or inadequate exercise. The sex differences in marital status, weight control, salt control, dyslipidaemia and uric acid were significant $(P<0.05$; see online supplementary material, Supplemental Table S2).

\section{Dietary patterns}

Four major dietary patterns, named the 'high protein' pattern, 'traditional northern' pattern, 'modern' pattern and 'condiments' pattern, were extracted (see online supplementary material, Supplemental Fig. S1). The total variance of these four dietary patterns was $27.754 \%$; the variance contribution rates were 9.017, 6.908, 6.645 and 5.184\%, respectively. Sex-specific dietary patterns are shown in Supplemental Tables S3 and S4 (Supplemental Figs S2 and S3). According to the variance, the order of the four major dietary patterns extracted was different between males and females, but the characteristics of food composition and the kinds of main foods in the four dietary patterns were basically the same. The 'high protein' pattern was characterized by milk tea and tea, fried wheat products, beef and mutton, milk and dairy products. The 'traditional northern' pattern represented a typical traditional diet: high intakes of starchy roots and products, pork, pickled vegetables/dried vegetables and corns. The 'modern' pattern featured the intake of various vegetables, fresh fruits, nuts and other foods. The 'condiments' pattern was characterized by high intakes of salt, animal oils, various condiments and various alcoholic beverages (Table 1).

\section{Characteristics of dietary patterns}

Table 2 shows the demographic characteristics of the four dietary patterns. The sex difference was significant in the distribution of the percentage in Q1 and Q4 of the 'high protein' pattern scores. There was an ascending trend for males and a declining trend for females $\left(P_{\text {trend }}=0.002\right)$. Of those showing the 'high protein' pattern, participants were younger, had higher educational levels, showed greater weight control and a higher percentage were in Q4. Most of the participants in Q4 (67.39\%) showed the 'high protein' pattern and engaged in adequate physical activity. Increasing factor scores were associated with a higher percentage of overweight and obese participants $\left(P_{\text {trend }}=0.002\right)$ and a lower percentage of hypertension patients $\left(P_{\text {trend }}=0 \cdot 012\right)$.

Participants with higher adherence to the 'traditional northern' pattern were from urban areas and were of
Table 1 Factor loadings of each dietary pattern found among Inner Mongolia adults ( $n$ 1861), northern China, 2015

\begin{tabular}{|c|c|c|c|c|}
\hline Food group & $\begin{array}{c}\text { 'High } \\
\text { protein' } \\
\text { pattern }\end{array}$ & $\begin{array}{c}\text { 'Traditional } \\
\text { northern' } \\
\text { pattern }\end{array}$ & $\begin{array}{l}\text { 'Modern' } \\
\text { pattern }\end{array}$ & $\begin{array}{l}\text { 'Condiments' } \\
\text { pattern }\end{array}$ \\
\hline Milk tea and tea & 0.795 & - & - & - \\
\hline $\begin{array}{l}\text { Fried wheat } \\
\text { products }\end{array}$ & 0.727 & - & - & - \\
\hline Beef/mutton & 0.627 & - & - & - \\
\hline Dairy products & 0.416 & - & - & - \\
\hline Milk & 0.371 & - & - & - \\
\hline Potato & - & 0.780 & - & - \\
\hline $\begin{array}{l}\text { Dried vegetables, } \\
\text { pickles }\end{array}$ & - & $0 \cdot 729$ & - & - \\
\hline Pork & - & 0.651 & - & - \\
\hline $\begin{array}{l}\text { Corn and other } \\
\text { cereals }\end{array}$ & - & 0.198 & - & - \\
\hline $\begin{array}{l}\text { Desserts, snacks, } \\
\text { snack foods }\end{array}$ & - & $0 \cdot 120$ & - & - \\
\hline Vegetables & - & - & 0.562 & - \\
\hline Soyabeans & - & - & 0.545 & - \\
\hline Wheat flour & - & - & 0.495 & - \\
\hline Fresh fruits & - & - & 0.458 & - \\
\hline Aquatic product & - & - & 0.427 & - \\
\hline Eggs & - & - & 0.425 & - \\
\hline Algae & - & - & 0.346 & - \\
\hline Vegetable oil & - & - & 0.254 & - \\
\hline Processed meat & - & - & 0.241 & - \\
\hline Starch and sugar & - & - & 0.236 & - \\
\hline Beverages & - & - & 0.114 & - \\
\hline Nuts & - & - & $0 \cdot 105$ & - \\
\hline Salt & - & - & - & 0.654 \\
\hline Animal oil & - & - & - & 0.607 \\
\hline Condiments & - & - & - & 0.528 \\
\hline Rice & - & - & - & 0.468 \\
\hline Alcohol & - & - & - & 0.318 \\
\hline Animal giblets & - & - & - & 0.180 \\
\hline Cake & - & - & - & -0.131 \\
\hline Variance (\%) & $9 \cdot 017$ & 6.908 & 6.465 & $5 \cdot 184$ \\
\hline
\end{tabular}

Han nationality. Most were married, unlike those with low factor scores. There was a sex difference in the distribution of the percentages in Q1 and Q4 of the "traditional northern' pattern; there was an ascending trend for males and a declining trend for females $\left(P_{\text {trend }}=0.001\right)$. The proportion of participants in Q4 decreased with increasing age ( $P_{\text {trend }}=0.012$ ); the $\geq 65$ years group had the lowest percentage $(16.01 \%)$. Non-smokers showing the 'traditional northern' pattern were more likely to have low factor scores. There was an ascending trend from Q1 to Q4 in the percentages of participants who controlled their salt intake, but hypertension patients showed the opposite trend.

Participants with higher adherence to the 'modern' pattern were male and from urban areas. They were younger than those who had low factor scores on the 'modern' pattern. Fewer older participants were in Q4 $(P<0.01)$; those aged $\geq 65$ years had the lowest percentage $(15.03 \%)$. Participants from other minorities had the highest percentage in Q4 (41.18\%). An ascending trend in the percentage in Q4 was observed as education level increased $(P<0 \cdot 01)$. Participants with high factor scores on the 'modern' pattern 


\section{Nublic Health Nutrition}

Table 2 Participant characteristics according to the lowest (Q1) and highest quartile (Q4) of each dietary pattern found among Inner Mongolia adults ( $n$ 1861), northern China, 2015

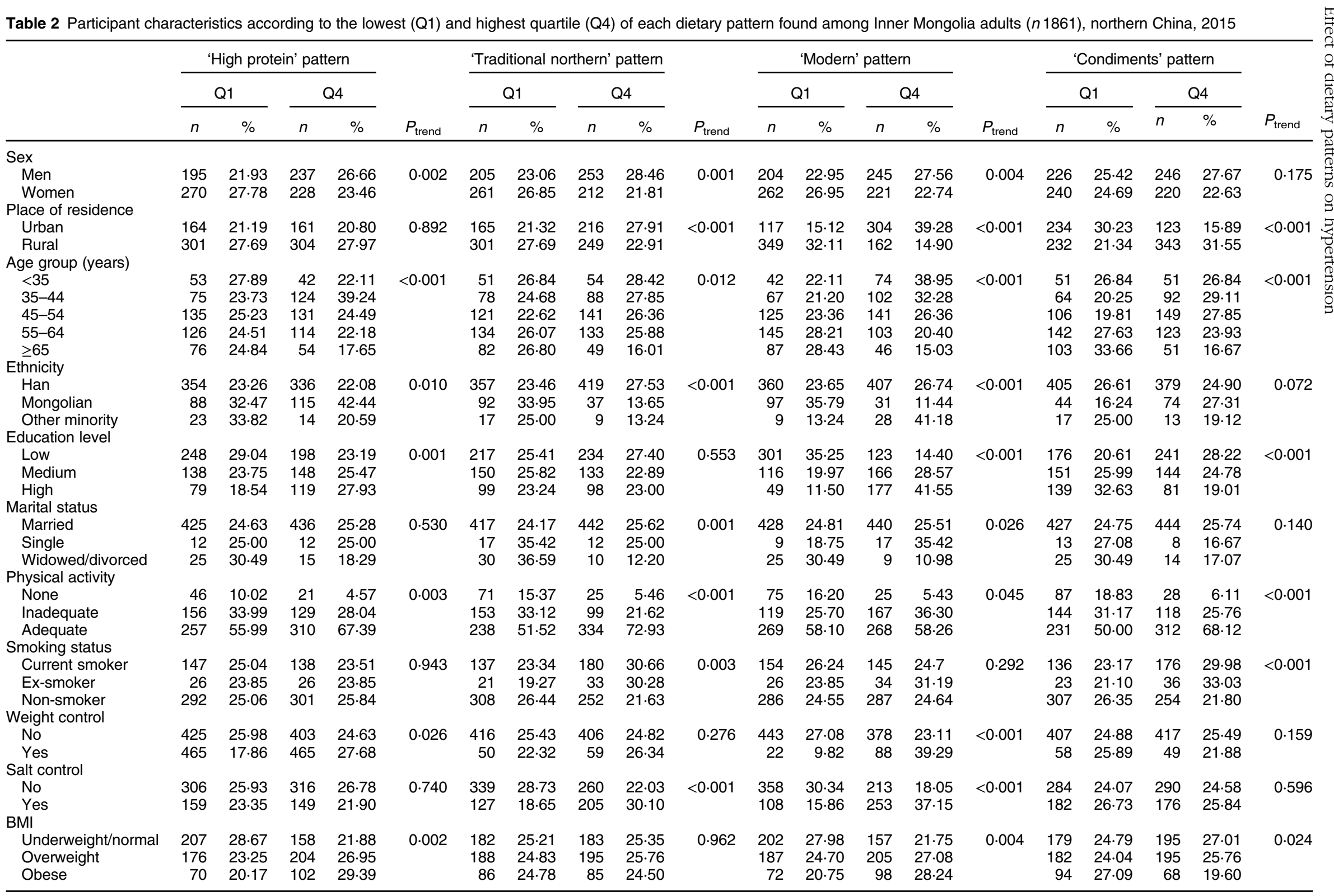


engaged in adequate physical activity and many did not control their weight.

Participants with higher adherence to the 'condiments' pattern were ethnic Mongolian males from rural areas. They had lower education levels, most were aged 35-54 years and they were more likely to smoke. An ascending trend in the percentage in Q4 was associated with an increased level of physical activity $\left(P_{\text {trend }}<0 \cdot 001\right)$. The percentage of people who controlled their salt intake and the percentage of hypertension patients increased from Q1 to Q4.

\section{Nutrient and energy intakes by dietary pattern}

Table 3 compares nutrient intakes in the four dietary patterns by sex. In the 'high protein' pattern, the intake of Ca was highest in males and females. Additionally, the percentage of energy from protein was also higher. However, the percentage of energy from dinner was lowest. Among the four dietary patterns, intakes of nutrients such as total fat and $\mathrm{K}$ were highest in the 'traditional northern' pattern in both sexes. In the 'modern' pattern, the intake of carbohydrates was highest in both males and females. Additionally, the percentage of energy from carbohydrates was also higher. Among the four dietary patterns, $\mathrm{Na}$ intake and the percentage of the energy from dinner were highest in the 'condiments' pattern in both sexes. However, the intakes of $\mathrm{Ca}$ and dietary fibre were lowest. The food consumption in the four dietary patterns by sex is shown in the online supplementary material, Supplemental Table S5.

\section{Quality evaluation of food intake using Dietary Balance Index-07 scores}

The distribution of dietary quality among Inner Mongolian adults is shown in the online supplementary material, Supplemental Table S6. In the total population, moderateand high-level dietary imbalance accounted for $79.64 \%$. Among them, the distribution of LBS indicated that $26.90 \%$ of the participants had high level of inadequate intakes, and the distribution of HBS indicated that $1.10 \%$ of the participants had high level of excessive intakes. The mean scores of LBS, HBS and DQD were 37.54, 4.73 and $42 \cdot 26$, respectively. Participants with hypertension had higher scores in LBS and DQD.

\section{Quality evaluation of dietary patterns using Dietary Balance Index-07 scores}

The quality of the 'high protein' pattern was higher as evaluated by DBI-07. Participants with higher factor scores in the 'high protein' pattern had lower DBI-07 scores: LBS $(\beta=-1.993 ; 95 \% \mathrm{CI}-2.362,-1.625 ; P<0.001)$, HBS $(\beta=$ $-0.206 ; 95 \% \mathrm{CI}-0.381,-0.030 ; P=0.021)$ and DQD $(\beta=-2 \cdot 199 ; 95 \% \mathrm{CI}-2 \cdot 598,-1 \cdot 801 ; P<0 \cdot 001)$. The quality of the 'condiments' pattern was lower. Participants with higher factor scores in the 'condiments pattern' had higher DBI-07 scores: LBS $(\beta=0.967 ; 95 \%$ CI $0.570,1.364$; 


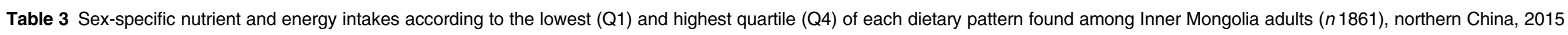

2

Males

Energy (kJ/d)

Energy (kcal/d)

Energy intake from

dinner $(\%)$
otal fat $(\mathrm{g} / \mathrm{d})$

Carbohydrate $(\mathrm{g} / \mathrm{d})$

Protein (g/d)

Energy intake from

carbohydrates (\%)

Energy intake from

fat (\%)

Energy intake from

protein (\%)

Fibre $(\mathrm{g} / \mathrm{d})$

$\mathrm{K}(\mathrm{g} / \mathrm{d})$

$\mathrm{K}(\mathrm{g} / \mathrm{d})$

$\mathrm{Na}(\mathrm{g} / \mathrm{d})$

Na:K

Energy $(\mathrm{kJ} / \mathrm{d})$

Energy (kcal/d)

Energy intake from

dinner (\%)

Total fat $(\mathrm{g} / \mathrm{d})$

Carbohydrate (

Protein $(\mathrm{g} / \mathrm{d})$

Energy intake from
carbohydrates $(\%)$

Energy intake from

fat $(\%)$

Energy intake from

Fibre $(\mathrm{g} / \mathrm{d})$

$\mathrm{Ca}(\mathrm{mg} / \mathrm{d})$

$\mathrm{K}(\mathrm{g} / \mathrm{d})$

$\mathrm{Na}(\mathrm{g} / \mathrm{d})$

$\mathrm{Na}$ K

\begin{tabular}{llll}
\multicolumn{3}{c}{ 'High protein' pattern } \\
\cline { 1 - 1 } Mean & SD & & \multicolumn{2}{c}{ Q4 } \\
Mean & SD
\end{tabular}

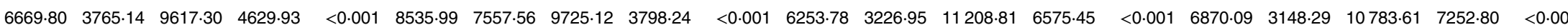

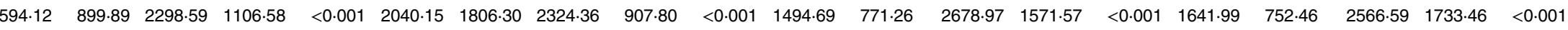

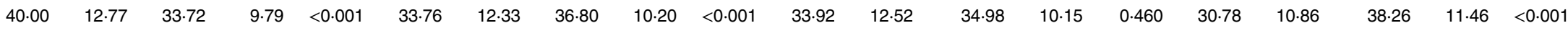

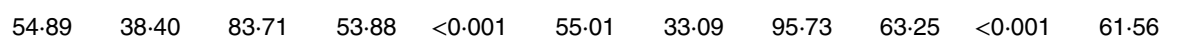

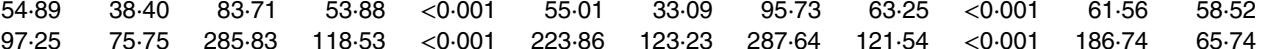

$\begin{array}{llllllllllll}36.57 & 16.68 & 75.40 & 31.31 & <0.001 & 47.22 & 24.56 & 68.72 & 32.26 & <0.001 & 41.91 & 26.13\end{array}$

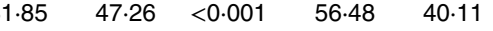

$84.07 \quad 59.24<0.001$

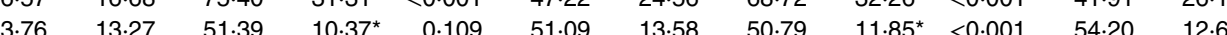

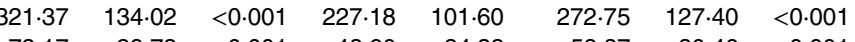

$\begin{array}{llllllll}73.17 & 29.73 & <0.001 & 48.60 & 24.32 & 58.87 & 30.46 & <0.001\end{array}$

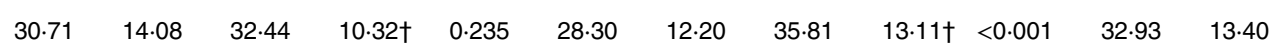

$29.37 \quad 10.58 \quad 0.017$

$29.89 \quad 10 \cdot 17$

$31.68 \quad 14.42 \dagger \quad 0.333$

$\begin{array}{llll}9.90 & 2.92 \quad 13.61 \quad 3.72 \dagger<0.001 \quad 11\end{array}$

$\begin{array}{rrrrrrrrrrrr}5.97 & 3.78 & 9.00 & 4.98 & <0.001 & 5.88 & 3.49 & 10.15 & 5.53 & <0.001 & 5.59 & 4.12\end{array}$

$\begin{array}{llllllllllll}186.77 & 93.70 & 390.28 & 192.71 & <0.001 & 300.79 & 170.91 & 336.08 & 189.45 & <0.001 & 236.84 & 203.18\end{array}$

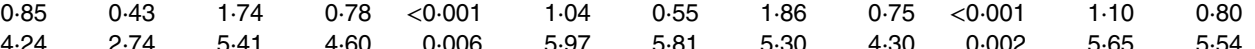

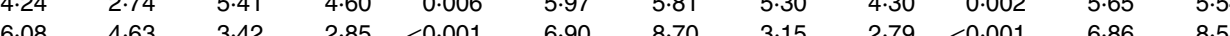

$\begin{array}{llllllllllll}5520.37 & 2375.63 & 8099.43 & 3651.54 & <0.001 & 5626.02 & 3011.85 & 9181.75 & 3556.48 & <0.001 & 5600.74 & 3187.33\end{array}$

$\begin{array}{llllllllllll}1319.40 & 567.79 & 1935.81 & 872.74 & <0.001 & 1344.65 & 719.85 & 2194.49 & 850.02 & <0.001 & 1338.61 & 761.79\end{array}$

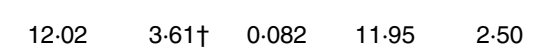

$\begin{array}{rrrrr}11.22 & 4.89 & <0.001 & 7.40 & 5.40\end{array}$

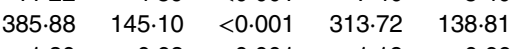

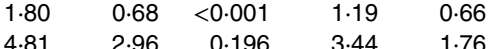

$2.92 \quad 1.85<0.001-3.55-1.23$

$8669.46 \quad 3818.11<0.001 \quad 5780.95 \quad 2266.05$

$2072.05 \quad 912.55 \quad<0.001 \quad 1381.68 \quad 541.60$

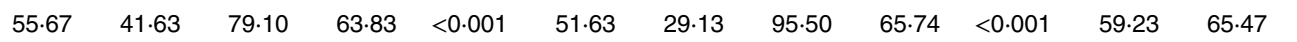

$\begin{array}{llllllllllll}166.41 & 62.57 & 239.01 & 112.34 & <0.001 & 167.96 & 70.80 & 267.62 & 120.34 & <0.001 & 161.72 & 60.61\end{array}$

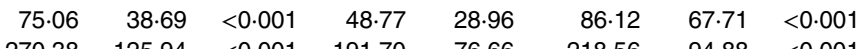

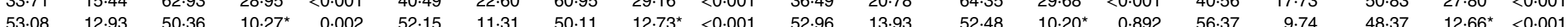

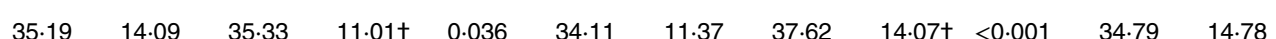

$\begin{array}{llll}33.11 & 10.60 \dagger & 0.442 \quad 30.80 & 10.12\end{array}$

$38.87 \quad 14.06 \dagger<0.001$

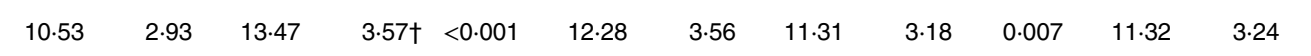

$\begin{array}{rrrrrrrrrrrr}6.10 & 3.93 & 8.09 & 5.11 & <0.001 & 5.68 & 3.96 & 9.79 & 5.95 & <0.001 & 5.02 & 3.56 \\ 181.16 & 99.99 & 363.75 & 187.76 & <0.001 & 282.30 & 177.55 & 327.07 & 203.76 & <0.001 & 231.24 & 207.12\end{array}$

$\begin{array}{rrrrrrrrrrrr}181.16 & 99.99 & 363.75 & 187.76 & <0.001 & 282.30 & 177.55 & 327.07 & 203.76 & <0.001 & 231.24 & 207.12 \\ 0.85 & 0.45 & 1.55 & 0.77 & <0.001 & 0.96 & 0.56 & 1.78 & 0.75 & <0.001 & 0.98 & 0.68\end{array}$

$\begin{array}{rrrrr}11.14 & 5.63 & <0.001 & 6.87 & 4.95\end{array}$

$\begin{array}{lll}7.69 & 4.83 & 0.014\end{array}$

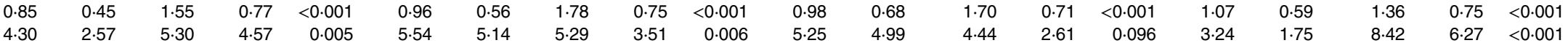

*Compared with Q1, the mean \pm SD is lower than the reference range.

†Compared with $\mathrm{Q} 1$, the mean $\pm \mathrm{SD}$ is higher than the reference range. 
Table 4 Generalized linear models* of dietary quality according to indicators of the Chinese Dietary Balance Index-07 (DBI-07) for each dietary pattern found among Inner Mongolia adults ( $n$ 1861), northern China, 2015

\begin{tabular}{|c|c|c|c|c|c|c|c|c|c|}
\hline & \multicolumn{3}{|c|}{ LBS } & \multicolumn{3}{|c|}{ HBS } & \multicolumn{3}{|c|}{ DQD } \\
\hline & $\beta$ & $95 \% \mathrm{Cl}$ & $P$ & $\beta$ & $95 \% \mathrm{Cl}$ & $P$ & $\beta$ & $95 \% \mathrm{Cl}$ & $P$ \\
\hline 'High protein' pattern & -1.993 & $-2 \cdot 362,-1 \cdot 625$ & $<0.001$ & -0.206 & $-0.381,-0.030$ & 0.021 & $-2 \cdot 199$ & $-2 \cdot 598,-1 \cdot 801$ & $<0.001$ \\
\hline 'Traditional northern' pattern & -0.690 & $-1.084,-0.295$ & 0.001 & 1.567 & $1.398,1.735$ & $<0.001$ & 0.877 & $0.451,1.308$ & $<0.001$ \\
\hline 'Modern' pattern & $-4 \cdot 882$ & $-5 \cdot 255,-4.508$ & $<0.001$ & 0.739 & $0.540,0.937$ & $<0.001$ & $-4 \cdot 143$ & $-4.574,-3.712$ & $<0.001$ \\
\hline 'Condiments' pattern & 0.967 & $0.570,1.364$ & $<0.001$ & 0.751 & $0.570,0.933$ & $<0.001$ & 1.718 & $1 \cdot 293,2 \cdot 143$ & $<0.001$ \\
\hline
\end{tabular}

LBS, lower-bound score; HBS, higher-bound score; DQD, diet quality distance.

*Model adjusted for sex, age, place of residence, educational level, marital status, nationality, salt intake control, smoking status, weight control, BMI, hypertension, abnormal blood lipids and other variables.

$P<0.001)$, HBS $(\beta=0.751 ; 95 \%$ CI $0.570,0.933 ; P<0.001)$ and DQD $(\beta=1.718 ; 95 \%$ CI $1.293,2.143 ; P<0.001)$. Higher adherence to the 'traditional northern' pattern was with lower LBS and higher HBS and DQD, and higher adherence to the 'modern' pattern was with lower LBS, DQD and higher HBS, respectively, which indicates diet quality was lower (Table 4). The results of evaluation of dietary quality in the different dietary patterns are shown in the online supplementary material, Supplemental Table S7.

\section{Association between dietary patterns and bypertension}

The 'high protein' pattern showed statistically significant inverse associations with hypertension in males, but no associations in females. In males, after adjusting for demographic and behavioural characteristics, the OR for hypertension in the highest quartile compared with the lowest was 0.406 (95\% CI 0.268, 0.615; $\left.P_{\text {trend }}=0.001\right)$; after further adjustment for BMI, the OR still less than 1, 0.374 (95\% CI 0.244, 0.573; $\left.P_{\text {trend }}<0.001\right)$. The 'condiments' pattern showed statistically significant positive associations with hypertension both in males and females. In males, after adjusting for demographic and behavioural characteristics and BMI, the OR for hypertension in the highest quartile compared with the lowest was $1.663\left(95 \% \mathrm{CI} 1.113,2.483 ; P_{\text {trend }}=0.005\right)$. In females, after adjusting for demographic and behavioural characteristics, the OR for hypertension in the highest quartile compared with the lowest quartile was 1.634 (95\% CI 1.067, 2.502; $\left.P_{\text {trend }}=0.037\right)$. After further adjustment for BMI, the OR increased to 1.788 (95\% CI 1.155, 2.766; $\left.P_{\text {trend }}=0.015\right)$. No associations between other dietary patterns and hypertension were observed (Tables 5 and 6).

\section{Discussion}

The prevalence of hypertension was $49.11 \%$ in Inner Mongolia, which is higher than the rate reported in northern China ${ }^{(17)}$ and a national survey ${ }^{(2)}$. Lower diet quality as evaluated by DBI-07 was prominent in Inner Mongolia. Epidemiological evidence shows that the risk of hypertension is associated with sociodemographic, lifestyle, behavioural, genetic and dietary factors ${ }^{(18,19)}$, especially closely with dietary quality. The present crosssectional study aimed to explore the association between the risk of hypertension and dietary quality as evaluated by the Chinese DBI-07 in Inner Mongolia in 2015.

Many studies ${ }^{(20,21)}$ have suggested that the DASH dietary pattern can prevent and control hypertension. The DASH diet mainly recommends the consumption of whole-wheat bread, spinach salad, olive oil, aquatic products and other foods. Inner Mongolia is located in northern China, and for geographical and economic reasons, residents consume small amounts of fresh vegetables and fruit. Although the consumption of fresh vegetables and fruit has increased in recent years, consumption remains lower than the recommended amount. A food culture that features meat as the main component still exists among local residents. Additionally, a large amount of alcohol consumption is associated with an increased risk of hypertension for males, particularly Asians, which is also a major feature in Inner Mongolia. Therefore, the DASH dietary pattern is not appropriate for evaluating the dietary quality of people in Inner Mongolia. Ultimately, we chose the Chinese DBI-07 to evaluate the dietary quality of residents in Inner Mongolia. Distinct from the DASH dietary pattern, the DBI-07 considers the effect of alcohol consumption. Moreover, the DBI-07 is based on the recommended amounts of various foods from the Dietary Guidelines for Chinese Residents. The DBI-07 evaluated the quality of different food intakes based on the consumption patterns of individuals with different energy intake needs. Compared with the recommended intakes of the Chinese Dietary Guidelines (2016) ${ }^{(22)}$, the lower quality diet of Inner Mongolia residents was serious, especially the inadequate intakes.

The characteristics of food composition and the kinds of main foods in each of the four dietary patterns extracted were basically the same by sex. Therefore, we named them as 'high protein' pattern, 'traditional northern' pattern, 'modern' pattern and 'condiments' pattern in both sexes. And the cumulative variance of these four dietary patterns was $27.754 \%$, which is close to that found in other research ${ }^{(23,24)}$. 
Table 5 Association of dietary patterns with hypertension across quartiles (Q) of dietary pattern scores in male Inner Mongolia adults (n889), northern China, 2015

\begin{tabular}{|c|c|c|c|c|c|c|c|c|c|}
\hline & & \multirow{2}{*}{ 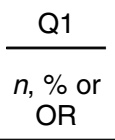 } & \multicolumn{2}{|r|}{ Q2 } & \multicolumn{2}{|r|}{ Q3 } & \multicolumn{2}{|c|}{ Q4 } & \multirow[b]{2}{*}{$P_{\text {trend }}$} \\
\hline & & & $\begin{array}{l}n, \% \text { or } \\
\text { OR }\end{array}$ & $95 \% \mathrm{Cl}$ & $\begin{array}{l}n, \% \text { or } \\
\text { OR }\end{array}$ & $95 \% \mathrm{Cl}$ & $\begin{array}{l}n, \% \text { or } \\
\text { OR }\end{array}$ & $95 \% \mathrm{Cl}$ & \\
\hline \multirow[t]{6}{*}{ 'High protein' pattern } & Cases $(n)$ & 127 & 98 & - & 132 & - & 106 & - & - \\
\hline & Proportion (\%) & 65.13 & 45.58 & - & 54.55 & - & 44.73 & - & - \\
\hline & Model 1 & 1.000 & 0.448 & $0.301,0.668$ & 0.643 & $0.436,0.947$ & 0.433 & $0.293,0.640$ & 0.001 \\
\hline & Model 2 & 1.000 & 0.384 & $0.250,0.589$ & 0.566 & $0.373,0.859$ & 0.391 & $0.257,0.595$ & 0.001 \\
\hline & Model 3 & 1.000 & 0.380 & $0.248,0.581$ & 0.511 & $0.334,0.781$ & 0.406 & $0.268,0.615$ & 0.001 \\
\hline & Model 4 & 1.000 & 0.408 & $0.264,0.630$ & 0.511 & $0.334,0.781$ & 0.374 & $0.244,0.573$ & $<0.001$ \\
\hline \multirow{6}{*}{$\begin{array}{l}\text { 'Traditional northern' } \\
\text { pattern }\end{array}$} & Cases $(n)$ & 110 & 112 & - & 129 & - & 112 & - & - \\
\hline & Proportion (\%) & 50.64 & 53.59 & - & $58 \cdot 11$ & - & 44.27 & - & - \\
\hline & Model 1 & 1.000 & 0.997 & $0.678,1.467$ & $1 \cdot 198$ & $0.817,1.756$ & 0.686 & $0.474,0.993$ & 0.081 \\
\hline & Model 2 & 1.000 & 0.961 & $0.639,1.445$ & $1 \cdot 215$ & $0.812,1.819$ & 0.686 & $0.463,1.016$ & 0.066 \\
\hline & Model 3 & 1.000 & 0.978 & $0.648,1.475$ & $1 \cdot 217$ & $0.811,1.826$ & 0.705 & $0.474,1.048$ & 0.153 \\
\hline & Model 4 & 1.000 & 1.047 & $0.687,1.598$ & $1 \cdot 263$ & $0.834,1.912$ & 0.677 & $0.452,1.014$ & 0.094 \\
\hline \multirow[t]{6}{*}{ 'Modern' pattern } & Cases $(n)$ & 103 & 113 & - & 124 & - & 123 & - & - \\
\hline & Proportion (\%) & 50.49 & $53 \cdot 30$ & - & 54.39 & - & $50 \cdot 20$ & - & - \\
\hline & Model 1 & 1.000 & $1 \cdot 119$ & $0.762,1.645$ & $1 \cdot 169$ & $0.801,1.707$ & 0.989 & $0.682,1.433$ & 0.967 \\
\hline & Model 2 & 1.000 & 1.220 & $0.812,1.831$ & 1.236 & $0.824,1.852$ & 1.185 & $0.789,1.780$ & 0.442 \\
\hline & Model 3 & 1.000 & $1 \cdot 206$ & $0.803,1.810$ & $1 \cdot 129$ & $0.756,1.687$ & 1.074 & $0.722,1.598$ & 0.841 \\
\hline & Model 4 & 1.000 & 1.139 & $0.752,1.727$ & $1 \cdot 128$ & $0.749,1.701$ & 0.956 & $0.635,1.440$ & 0.799 \\
\hline \multirow[t]{6}{*}{ 'Condiments' pattern } & Cases $(n)$ & 107 & 105 & - & 119 & - & 132 & - & - \\
\hline & Proportion (\%) & 47.35 & $50 \cdot 97$ & - & $56 \cdot 40$ & - & $53 \cdot 66$ & - & - \\
\hline & Model 1 & 1.000 & $1 \cdot 156$ & $0.792,1.687$ & 1.439 & $0.987,2.098$ & 1.288 & $0.897,1.849$ & 0.106 \\
\hline & Model 2 & 1.000 & $1 \cdot 150$ & $0.769,1.718$ & 1.564 & $1 \cdot 044,2 \cdot 344$ & 1.584 & $1 \cdot 070,2 \cdot 346$ & 0.009 \\
\hline & Model 3 & 1.000 & 1.205 & $0.806,1.799$ & 1.619 & $1.083,2.421$ & 1.718 & $1 \cdot 160,2.545$ & 0.003 \\
\hline & Model 4 & 1.000 & $1 \cdot 102$ & $0.729,1.666$ & 1.496 & $0.992,2.254$ & 1.663 & $1.113,2.483$ & 0.005 \\
\hline
\end{tabular}

Data were analysed using multivariable-adjusted logistic regression.

Model 1: crude model.

Model 2: adjusted for age place of residence, ethnicity, marital status, educational level, family history and dyslipidaemia.

Model 3: additionally adjusted for smoking status, physical activity, weight control and salt control.

Model 4: additionally adjusted for BMI.

The 'high protein' pattern was characterized by milk tea and tea, fried wheat products, beef and mutton, milk and dairy products. The LBS, HBS and DQD indicators of DBI-07 showed a descending trend as the factor scores increased in the 'high protein' pattern. The dietary intake of meat and dairy products, and the intakes of nutrients such as protein and $\mathrm{Ca}$, were higher than in the other dietary patterns. The energy intake at dinner was lower than for the other patterns. Male participants who mainly adhered to the 'high protein' pattern had a lower risk of hypertension, while in females the 'high protein' pattern was not significantly associated with hypertension. The possible reason is that intakes of protein and $\mathrm{Ca}$, which benefited to control blood pressure ${ }^{(25,26)}$, were lower in females than in males. In addition, the 'high protein' pattern in the present study was not the main dietary pattern in females, but the 'traditional northern' pattern. Other authors ${ }^{(27,28)}$ also showed that a dietary pattern high in protein was associated with a reduced risk of hypertension. Although the intake of meat is a risk factor for hypertension $^{(29-31)}$, our study did not show that the 'high protein' dietary pattern with consumption of beef and mutton was a risk factor for hypertension after adjusting for confounders. On one hand, the fat content of beef and mutton is lower than that of pork ${ }^{(32)}$, and the other hand, dairy products are rich in protein and $\mathrm{Ca}$. The high intake of protein makes people feel full quickly, which helps to eat less high-energy foods and improves the whole dietary quality to reduce blood pressure ${ }^{(25,33)}$. Moreover, Ca contributes to reduce the incidence of obesity through shifting the energy balance, thereby reducing the risk of suffering hypertension ${ }^{(26)}$. A notable feature of the 'high protein' dietary pattern was the high intake of milk tea and tea; of them, tea has a positive effect on blood pressure and blood lipids ${ }^{(34)}$.

The 'condiments' pattern was characterized by high intakes of salt, animal oil, condiments and alcoholic beverages. The LBS, HBS and DQD indicators of DBI-07 showed an ascending trend as the factor scores increased. In the 'condiments' pattern, the dietary intake of oil and salt was higher than the recommended intake, and the dietary intake of vegetables, eggs and dairy was lower than the recommended intake. Participants had a higher risk of hypertension in the 'condiments' pattern. Factor score in the 'condiments' pattern was positively correlated with waist and lipid-related indicators, and thus it was also positively correlated with the prevalence of hypertension ${ }^{(35,36)}$. It is worth noting that the intake of alcohol in the 'condiments' dietary pattern is much higher than in the other three dietary patterns. Long-term excessive intake of alcohol is an independent risk factor for hypertension ${ }^{(37,38)}$. Participants with higher adherence to the 'condiments' 
Table 6 Association of dietary patterns with hypertension across quartiles (Q) of dietary pattern scores in female Inner Mongolia adults ( $n$ 972), northern China, 2015

\begin{tabular}{|c|c|c|c|c|c|c|c|c|c|}
\hline & & \multirow{2}{*}{ 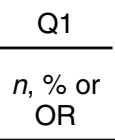 } & \multicolumn{2}{|r|}{ Q2 } & \multicolumn{2}{|r|}{ Q3 } & \multicolumn{2}{|c|}{ Q4 } & \multirow[b]{2}{*}{$P_{\text {trend }}$} \\
\hline & & & $\begin{array}{l}n, \% \text { or } \\
\text { OR }\end{array}$ & $95 \% \mathrm{Cl}$ & $\begin{array}{l}n, \% \text { or } \\
\text { OR }\end{array}$ & $95 \% \mathrm{Cl}$ & $\begin{array}{l}n, \% \text { or } \\
\text { OR }\end{array}$ & $95 \% \mathrm{Cl}$ & \\
\hline \multirow[t]{6}{*}{ 'High protein' pattern } & Cases $(n)$ & 132 & 116 & - & 94 & - & 109 & - & - \\
\hline & Proportion (\%) & 48.89 & $46 \cdot 40$ & - & 41.96 & - & $47 \cdot 81$ & - & - \\
\hline & Model 1 & 1.000 & 0.905 & $0.641,1.277$ & 0.756 & $0.529,1.080$ & 0.958 & $0.673,1.363$ & 0.559 \\
\hline & Model 2 & 1.000 & 0.746 & $0.502,1.109$ & 0.640 & $0.425,0.963$ & 1.136 & $0.755,1.709$ & 0.839 \\
\hline & Model 3 & 1.000 & 0.746 & $0.502,1.109$ & 0.640 & $0.425,0.963$ & $1 \cdot 136$ & $0.755,1.709$ & 0.839 \\
\hline & Model 4 & 1.000 & 0.675 & $0.448,1.015$ & 0.570 & $0.375,0.868$ & 0.992 & $0.654,1.504$ & 0.677 \\
\hline \multirow{6}{*}{$\begin{array}{l}\text { 'Traditional northern' } \\
\text { pattern }\end{array}$} & Cases $(n)$ & 126 & 133 & - & 100 & - & 92 & - & - \\
\hline & Proportion (\%) & 48.28 & 51.95 & - & 41.15 & - & 43.40 & - & - \\
\hline & Model 1 & 1.000 & $1 \cdot 159$ & $0.820,1.636$ & 0.749 & $0.731,1.223$ & 0.821 & $0.571,1.182$ & 0.081 \\
\hline & Model 2 & 1.000 & 0.957 & $0.647,1.417$ & 0.698 & $0.467,1.041$ & 0.749 & $0.493,1.140$ & 0.069 \\
\hline & Model 3 & 1.000 & 0.957 & $0.647,1.417$ & 0.698 & $0.467,1.041$ & 0.749 & $0.493,1.140$ & 0.069 \\
\hline & Model 4 & 1.000 & 1.002 & $0.670,1.499$ & 0.698 & $0.463,1.051$ & 0.782 & $0.511,1.198$ & 0.097 \\
\hline \multirow[t]{6}{*}{ 'Modern' pattern } & Cases $(n)$ & 134 & 120 & - & 114 & - & 83 & - & - \\
\hline & Proportion (\%) & $51 \cdot 15$ & 47.43 & - & 48.31 & - & 37.56 & - & - \\
\hline & Model 1 & 1.000 & 0.862 & $0.610,1.218$ & 0.893 & $0.628,1.269$ & 0.575 & $0.399,0.827$ & 0.007 \\
\hline & Model 2 & 1.000 & 0.774 & $0.524,1.142$ & 0.867 & $0.573,1.302$ & 0.694 & $0.449,1.072$ & 0.159 \\
\hline & Model 3 & 1.000 & 0.774 & $0.524,1.142$ & 0.867 & $0.573,1.302$ & 0.694 & $0.449,1.072$ & 0.159 \\
\hline & Model 4 & 1.000 & 0.765 & $0.514,1.137$ & 0.845 & $0.558,1.280$ & 0.650 & $0.417,1.015$ & 0.097 \\
\hline \multirow{6}{*}{ 'Condiments' pattern } & Cases $(n)$ & 104 & 123 & - & 115 & - & 109 & - & - \\
\hline & Proportion (\%) & 43.33 & 47.49 & - & $45 \cdot 46$ & - & 49.55 & - & - \\
\hline & Model 1 & 1.000 & 1.183 & $0.831,1.168$ & $1 \cdot 109$ & $0.764,1.555$ & 1.284 & $0.889,1.854$ & 0.106 \\
\hline & Model 2 & 1.000 & $1 \cdot 353$ & $0.903,2.026$ & $1 \cdot 312$ & $0.871,1.976$ & 1.634 & $1.067,2.502$ & 0.037 \\
\hline & Model 3 & 1.000 & 1.353 & $0.903,2.026$ & 1.312 & $0.871,1.976$ & 1.634 & $1.067,2.502$ & 0.037 \\
\hline & Model 4 & 1.000 & 1.403 & $0.928,2.120$ & 1.382 & $0.910,2.098$ & 1.788 & $1.155,2.766$ & 0.015 \\
\hline
\end{tabular}

Data were analysed using multivariable-adjusted logistic regression.

Model 1: crude model.

Model 2: adjusted for age, place of residence, ethnicity, marital status, educational level, family history and dyslipidaemia.

Model 3: additionally adjusted for smoking status, physical activity, weight control and salt control.

Model 4: additionally adjusted for BMI.

pattern had the highest HBS for alcohol consumption and the highest risk of hypertension. Dietary salt and Na intakes were also the highest in the 'condiments' dietary pattern. Salt consumption is associated with hypertension ${ }^{(39,40)}$. Long-term excessive intake of salt reduces the ability of the kidneys to process salt ${ }^{(41)}$, leading to impairments of endothelial function, left ventricular relaxation, electric repolarization, endothelium dysfunction ${ }^{(42)}$, and subsequent vascular sclerosis ${ }^{(43)}$, resulting in primary hypertension by affecting $\mathrm{Na}$ loadings.

The 'traditional northern' pattern was characterized by high intakes of starch and sugar, pork, pickled vegetables/ dried vegetables and corns; the dietary intake of cereals and meat was higher than the recommended intake, and the intakes of nutrients such as total fat and $\mathrm{Na}$ were also higher than recommended. The 'modern' pattern was characterized by the intakes of various vegetables, fresh fruits, nuts and other foods; the dietary intake of carbohydrates and $\mathrm{Na}$ was higher than the recommended intake, and intakes of the nutrients dietary fibre and $\mathrm{Ca}$ were lower than those recommended. In the 'traditional northern' pattern, the HBS and DQD indicators of DBI-07 ascended with increasing factor scores, although the LBS showed a descending trend. In the 'modern' pattern, HBS showed an ascending trend as the factor scores increased, even though LBS and DQD showed a descending trend. In our study, no association was found with hypertension.

Excessive intake of salt and alcohol is related to the development of hypertension ${ }^{(44-47)}$. In our study, salt consumption was excessive in the four major dietary patterns, as assessed by DBI-07. For those participants with higher factor scores in the 'traditional northern' pattern and the 'modern' pattern, although they have no higher $\mathrm{Na}$ intake as factor scores increased compared with the 'high protein' pattern and the 'condiments' pattern, we did not find they were related to a lower risk of hypertension. The 'condiments' pattern had the highest intake of alcohol compared with the other three dietary patterns and showed a risk factor for hypertension. And the alcohol consumption in the 'high protein' pattern was higher than in the 'traditional northern' pattern. However, participants had a lower risk of hypertension if they mainly followed the 'high protein' pattern. Based on the excessive salt intake in the four major dietary patterns, and the higher alcohol consumption in the 'high protein' pattern than in the 'traditional northern' pattern, only the 'high protein' dietary pattern indicated a reduced hypertension risk, we suggest that the quality of dietary pattern evaluated by DBI-07 may explain the important part effect on hypertension. Evidence to support this assumption comes from a Japanese study ${ }^{(37)}$, which 
indicated that the higher the dietary quality and the more high quality diet, the lower the hypertension risk.

There is a close relationship between BMI and hypertension $^{(48)}$. The present study focused on the relationship between the quality of dietary patterns and hypertension. In males, after adjusting for BMI, the OR of the 'high protein' pattern with higher quality and risk of hypertension changed from 0.406 (95\% CI 0.268, $0.615)$ to 0.374 (95\% CI $0.244,0.573)$. In females, after adjusting for BMI, the OR of the 'condiments' pattern with lower quality and risk of hypertension changed from 1.634 (95\% CI 1.067, 2.502) to 1.788 (95\% CI 1.155, 2.766). After adjusting for BMI, the dietary quality was still the primary factor for hypertension.

Sociodemographic features generally affect people's dietary pattern and quality ${ }^{(49)}$. Our study mainly evaluated the relationship between the quality of current dietary patterns and hypertension. Therefore, demographic characteristics were only used as confounders for adjustment. We did not explore further their effect on the relationship between dietary patterns and hypertension in the present study.

The present study was cross-sectional. Despite effective methods of quality control, a certain amount of bias (including selection bias, information bias and other types of bias) is unavoidable and may have affected the representativeness of the sample and results. Although the study demonstrated a relationship between excessive/insufficient food intake and hypertension, and between dietary patterns and hypertension, causal relationships cannot be assumed. The findings offer some insights into the aetiology of the association between dietary patterns and hypertension; however, longterm follow-up studies are needed to determine if there is a causal relationship between these factors.

\section{Conclusions}

In summary, four major dietary patterns were identified; the 'high protein' pattern (a higher-quality dietary pattern as evaluated by DBI-07) was related to a decreased prevalent risk of hypertension, while the 'condiments' pattern (a lower-quality dietary pattern as evaluated by DBI-07) was related to an increased prevalent risk of hypertension.

\section{Acknowledgements}

Acknowledgements: The authors sincerely express appreciation to all the participants and to local colleagues. They thank Diane Williams, PhD, from Liwen Bianji, Edanz Group China (www.liwenbianji.cn/ac), for editing the English text of a draft of this manuscript. Financial support: This study was supported by Inner Mongolia Science and Technology Project (Intelligent Health Monitoring and Modern Medical Information System Development Based on Internet of Things Technology). The funder had no role in the design, analysis or writing of this article. Conflict of interest: None declared. Authorship: X.W. and P.W. conceived and designed the protocol. X.W. and A.L. conducted the statistical analysis and prepared the manuscript. M.D., J.W., W.W. and Y.Q. contributed to data collection. H.Z., D. Liu, X.N., L.J., R.S., D. Liang and R.W. participated in cleaning and analysing the data. X.W. and A.L. produced the final revised manuscript. P.W. reviewed the paper and approved its final version. All authors were involved in interpreting results, editing the manuscript for content and approved the final version of the manuscript. Ethics of human subject participation: This study was conducted according to the guidelines laid down in the Declaration of Helsinki and all procedures involving human subjects were approved by the Ethical Committee of the National Institute for Nutrition and Food Safety, Chinese Center for Disease Control and Prevention. Written informed consent was provided by participants before the start of the investigation.

\section{Supplementary material}

To view supplementary material for this article, please visit https://doi.org/10.1017/S136898001900301X

\section{References}

1. Zhou B, Bentham J, Cesare MD et al. (2017) Worldwide trends in blood pressure from 1975 to 2015: a pooled analysis of 1479 population-based measurement studies with 19.1 million participants. Lancet 389, 37-55.

2. Wang J, Zhang L, Wang F et al. (2014) Prevalence, awareness, treatment, and control of hypertension in China: results from a national survey. Am J Hypertens 27, 1355-1361.

3. Wu Y, Huxley R, Li L et al. (2008) Prevalence, awareness, treatment, and control of hypertension in China: data from the China National Nutrition and Health Survey 2002. Circulation 118, 2679-2686.

4. World Health Organization (2013) A global brief on hypertension. https://www.who.int/cardiovascular_diseases/ publications/global_brief_hypertension/en/ (accessed March 2013).

5. Daskalopoulou SS, Rabi DM \& Zarnke KB (2015) The 2015 Canadian Hypertension Education Program recommendations for blood pressure measurement, diagnosis, assessment of risk, prevention, and treatment of hypertension. Can J Cardiol 31, 549-568.

6. Kastorini CM \& Panagiotakos DB (2010) Mediterranean diet and diabetes prevention: myth or fact? World J Diabetes $\mathbf{1}$, 65-67.

7. Chrysohoou C, Pitsavos C, Metallinos G et al. (2012) Crosssectional relationship of a Mediterranean type diet to diastolic heart function in chronic heart failure patients. Heart Vessels 27, 576-584.

8. Sacks FM, Svetkey P, Vollmer WM et al. (2001) Effects on blood pressure of reduced dietary sodium and the Dietary Approaches to Stop Hypertension (DASH) diet. DASHSodium Collaborative Research Group. $N$ Engl J Med 344, $3-10$.

9. Wang D, He Y, Li Y et al. (2011) Dietary patterns and hypertension among Chinese adults: a nationally representative cross-sectional study. BMC Public Health 11, 925. 
10. Li G, Wang H, Wang K et al. (2014) Prevalence, awareness, treatment, control and risk factors related to hypertension among urban adults in Inner Mongolia 2014: differences between Mongolian and Han populations. BMC Public Health 16, 294.

11. Wang SS, Lay S, Yu HN et al. (2016) Dietary Guidelines for Chinese Residents (2016): comments and comparisons. J Zhejiang Univ Sci B 17, 649-656.

12. Xu X, Hall J, Byles J et al. (2015) Assessing dietary quality of older Chinese people using the Chinese Diet Balance Index (DBI). PLoS One 10, e0121618.

13. Zang J, Yu H, Zhu Z et al. (2017) Does the dietary pattern of Shanghai residents change across seasons and area of residence: assessing dietary quality using the Chinese Diet Balance Index (DBI). Nutrients 9, 251.

14. Du M, Yin S, Wang P et al. (2018) Self-reported hypertension in Northern China: a cross-sectional study of a risk prediction model and age trends. BMC Health Serv Res 18, 475.

15. Ainsworth BE, Haskell WL, Whitt MC et al. (2000) Compendium of physical activities: an update of activity codes and MET intensities. Med Sci Sports Exerc 32, 9 Suppl., S498-S516.

16. Zhou B (2002) Predictive values of body mass index and waist circumference for risk factors of certain related diseases in Chinese adults - study on optimal cut-off points of body mass index and waist circumference in Chinese adults. Biomed Environ Sci 15, 83-96.

17. Yanlei P, Zengwu W, Xin W et al. (2015) A prevalence survey of cardiovascular risk factors and hypertension in northern rural areas of China. Chin J Dis Control $\mathbf{4}$, 327-329, 341.

18. Horn LV, Tian L, Neuhouser ML et al. (2012) Dietary patterns are associated with disease risk among participants in the Women's Health Initiative Observational Study. J Nutr 142, 284-291.

19. Hong X, Li J-Q, Wang Z-Y et al. (2013) Dietary patterns and hyperglycemia in a follow-up study in Nanjing city. Chin J Prev Med 47, 135-141.

20. Saneei P, Salehi-Abargouei A, Esmaillzadeh A et al. (2014) Influence of Dietary Approaches to Stop Hypertension (DASH) diet on blood pressure: a systematic review and meta-analysis on randomized controlled trials. Nutr Metab Cardiovasc Dis 24, 1253-1261.

21. Siervo M, Lara J, Chowdhury S et al. (2015) Effects of the Dietary Approach to Stop Hypertension (DASH) diet on cardiovascular risk factors: a systematic review and metaanalysis. BrJ Nutr 113, 1-15.

22. Yang Y \& Zhang H (2016) Introduction of Chinese residents' dietary guidelines. Acta Nutrimenta Sinica 38, 209-217.

23. Gao J (2012) Association of dietary patterns and physical activities with total body fat proportions and metabolic syndrome among middle-aged and elderly people: a crosssectional study. PhD Thesis, Fudan University.

24. Kim JH, Ji EL \& Jung IK (2012) Dietary pattern classifications and the association with general obesity and abdominal obesity in Korean women. J Am Acad Nutr Diet 112, 1550-1559.

25. Buendia JR, Bradlee ML \& Singer MR et al. (2015) Diets higher in protein predict lower high blood pressure risk in Framingham Offspring Study adults. Am J Hypertens 28, 372-379.

26. Teegarden D (2003) Calcium intake and reduction in weight or fat mass. J Nutr 133, issue 1, 249S-251S.

27. Wang Y (2012) Dietary patterns and hypertension among adults in Taiwan. Health Res 41, 14-19.

28. Zhao T, Chu Y, Zhao H et al. (2016) Survey analysis on relationship between dietary patterns and hypertension of residents in rural areas of Jilin Province. J Jilin Univ (Med Ed) 42, 400-404.

29. Conlin PR, Chow D, Miller ER et al. (2000) The effect of dietary patterns on blood pressure control in hypertensive patients: results from the Dietary Approaches to Stop Hypertension (DASH) trial. Am J Hypertens 13, 949-955.

30. van den Brandt PA (2019) Red meat, processed meat, and other dietary protein sources and risk of overall and causespecific mortality in the Netherlands Cohort Study. Eur J Epidemiol 34, 351-369.

31. Rohrmann S, Overvad K, Bueno-de-Mesquita HB et al. (2013) Meat consumption and mortality - results from the European Prospective Investigation into Cancer and Nutrition. BMC Med 11, 63.

32. Ekpo EB, Udofia O, Eshiet NF et al. (1992) Demographic, life style and anthropometric correlates of blood pressure of Nigerian urban civil servants, factory and plantation workers. J Hum Hypertens 6, 275-280.

33. Martini LA \& Wood RJ (2009) Milk intake and the risk of type 2 diabetes mellitus, hypertension and prostate cancer. Arq Bras Endocrinol Metab 53, 688-694.

34. Li Y, Li S, Wang L et al. Burden of disease attributable to main behavioral risk factor of chronic disease inactivity in China, 1990 and 2010. Chin J Prev Med 4, 303-308.

35. Zhu T, Fang Z, Yang $\mathrm{H}$ et al. (2016) Application of factor analysis and structural equation model in the relationship between dietary patterns and hypertension. Chin J Health Stat 33, 16-19.

36. Zhao T (2016) The investigation and analysis of relationship between dietary patterns and hypertension of the elderly Han nationality and Korean nationality residents in rural areas of Jilin Province. Master Thesis, Jilin University.

37. Roerecke M, Tobe SW, Kaczorowski J et al. (2018) Sexspecific associations between alcohol consumption and incidence of hypertension: a systematic review and metaanalysis of cohort studies. J Am Heart Assoc 7, e008202.

38. Wood AM, Kaptoge S, Butterworth AS et al. (2018) Risk thresholds for alcohol consumption: combined analysis of individual-participant data for 599912 current drinkers in 83 prospective studies. Lancet 391, 1513-1523.

39. Lei L \& Wang JG (2018) Dietary sodium intake and serum uric acid: a mini-review. Pulse (Basel) 6, 124-129.

40. Campagnoli T, Gonzalez L \& Santa Cruz F (2012) Salt intake and blood pressure in the University of Asuncion-Paraguay youths: a preliminary study. J Bras Nefrol 34, 361-368.

41. Meneton P, Jeunemaitre X, Wardener HE et al. (2005) Links between dietary salt intake, renal salt handling, blood pressure, and cardiovascular diseases. Physiol Rev 85, 679-715.

42. Tzemos N, Lim PO, Wong S et al. (2008) Adverse cardiovascular effects of acute salt loading in young normotensive individuals. Hypertension 51, 1525-1530.

43. Bragulat E, de la Sierra A, Antonio MT et al. (2001) Endothelial dysfunction in salt-sensitive essential hypertension. Hypertension 37, 444-448.

44. Silman AJ, Locke C, Mitchell P et al. (1983) Evaluation of the effectiveness of a low sodium diet in the treatment of mild to moderate hypertension. Lancet 1, 1179-1182.

45. Du S, Batis C, Wang H et al. (2014) Understanding the patterns and trends of sodium intake, potassium intake, and sodium to potassium ratio and their effect on hypertension in China. Am J Clin Nutr 99, 334-343.

46. Ravi S, Bermudez OI, Harivanzan V et al. (2016) Sodium intake, blood pressure, and dietary sources of sodium in an adult South Indian population. Ann Glob Health 82, 234-242.

47. Kazim S, Ansari RA \& Husain K (2016) Alcoholic beveragesinduced hypertension and its management. World J Pharm Life Sci 2, 311-338.

48. Rahman M, Williams G \& Mamun AA (2017) Hypertension and diabetes prevalence among adults with moderately increased BMI $\left(23.0-24.9 \mathrm{~kg} / \mathrm{m}^{2}\right)$ : findings from a nationwide survey in Bangladesh. Public Health Nutr 20, 1343-1350.

49. Darmon N \& Drewnowski A (2008) Does social class predict diet quality? Am J Clin Nutr 87, 1107-1111. 